\title{
Effects of Hydrodynamics on Soot Formation in Laminar Opposed-Jet Diffusion Flames
}

\author{
K.-C. Lin* and G. M. Faeth $\dagger$ \\ University of Michigan, Ann Arbor, Michigan 48109-2118
}

\begin{abstract}
Effects of flow (hydrodynamic) properties on the presence of soot in hydrocarbon-fueled laminar opposed-jet diffusion flames were studied experimentally at atmospheric pressure, emphasizing effects of velocities normal to the flame sheet. These velocities were varied for conditions corresponding to combustion in air by transferring nitrogen from the oxidizer stream to the fuel stream, which increases the stoichiometric mixture fraction of the flame and causes the stagnation plane of the flow to shift toward the fuel-rich side of the flame sheet. Fuels considered included acetylene, ethylene, ethane, propylene, propane, and 1-3 butadiene. Present measurements consisted of the critical strain rates for the flames to contain soot (the soot extinction limit) and for the flames to extinguish (the fiame extinction limit). It was found that increasing the stoichiometric mixture fraction causes a progressive reduction of the critical strain rates for both flame and soot extinction; however, their ratio increases, and even becomes unbounded in most instances to yield a permanently-blue-flame regime. The results suggest that soot formation in nonpremixed flames can be controlled by varying velocities normal to the flame sheet. Nevertheless, definitive conclusions along these lines require evaluation of effects of corresponding variations of fuel and oxygen concentrations on soot formation when velocities normal to the flame sheet are changed by varying stoichiometric mixture fractions for laminar opposed-jet diffusion flames.
\end{abstract}

\section{Nomenclature}

EST = strain rate estimated from Eq. (4)

$K=$ strain rate

$L \quad=$ nozzle separation distance

LDV = strain rate measured directly by laser Doppler velocimetry

$\boldsymbol{u}=$ radial velocity

$v \quad=$ streamwise velocity

$W_{i}=$ molecular weight of species $i$

$Y_{i} \quad=$ mass fraction of species $i$

$Z_{\text {st }} \quad=$ stoichiometric mixture fraction

$z=$ streamwise distance

$\nu_{i} \quad=$ stoichiometric coefficient of species $i$

$\rho \quad=$ density

\section{Subscripts}

$a \quad=$ initial property of oxidant stream

$E \quad=$ property at flame extinction limit

$F \quad=$ property of fuel

$f \quad=$ initial property of fuel stream

$L \quad=$ property at soot extinction limit

$O \quad=$ oxidant property

$P \quad=$ combustion product property

\section{Introduction}

$\mathbf{S}^{\mathrm{E}}$ EVERAL methods are available to control the content and emission of soot for hydrocarbon-fueled flames. Among these, soot-control strategies based on fast mixing are the most popular because they avoid the operational problems of additives and premixed combustion. ${ }^{1-3}$ The basic objective of fast mixing is to reduce the residence times of fuel and fuel decomposition species at fuel-rich conditions to limit the formation of soot precursor species and soot so that these mate-

Received Sept. 8, 1995; revision received March 1, 1996; accepted for publication March 9, 1996. Copyright (9) 1996 by the American Institute of Aeronautics and Astronautics, Inc. All rights reserved.

*Graduate Student Research Assistant, Department of Aerospace Engineering.

†Professor, Department of Aerospace Engineering. Fellow AIAA. rials can be oxidized completely within the flames. The present investigation seeks to extend earlier studies of fast mixing concepts using the laminar coflowing-jet diffusion flame configuration $^{4-8}$ to consider related concepts using the computationally more tractable laminar opposed-jet diffusion flame configuration. $^{9}$

While it is widely recognized that fast mixing reduces soot concentrations in diffusion flames, ${ }^{1-3}$ past work has shown that the mechanism of mixing is critical as well. ${ }^{4-9}$ An important aspect of the mixing mechanism is that flow velocities normal to the flame sheet significantly affect soot processes within nonpremixed flames. In particular, conditions that cause these velocities to be more directed from the fuel-rich toward the fuel-lean side of the flame sheet tend to reduce soot concentrations within the flame with a corresponding reduction of the tendency for soot to be emitted from the flame.

Velocities normal to the flame sheet in diffusion flames affect soot processes somewhat differently for gaseous soot precursor species and for soot particles. Effects of velocities normal to the flame sheet on soot precursor species are discussed by $\mathrm{Du}$ and Axelbaum ${ }^{9}$ and will be considered only briefly in the following. When velocities normal to the flame sheet are directed toward the fuel-lean region, they enhance the transport of fuel and soot precursor species toward the flame sheet, but inhibit the transport of energy from the flame sheet toward the fuel-rich conditions. These effects tend to increase the velocities of fuel and soot precursor species across the high-temperature region while constricting the width of the high-temperature region at fuel-rich conditions. This correspondingly reduces the residence times of these species at the high-temperature fuel-rich conditions needed for soot formation, which reduces the concentrations of soot precursor species and soot. In contrast, when these velocities are directed toward fuel-rich conditions, the transport of fuel and soot precursor species toward the flame sheet is retarded while the transport of energy from the flame sheet toward the fuel-rich conditions is enhanced. These effects tend to reduce the velocities of fuel and soot precursor species across the high-temperature region while increasing the width of the high-temperature region at fuel-rich conditions. This correspondingly increases the residence times of these species at the high-temperature fuel-rich 
conditions needed for soot formation, which enhances the formation of soot precursor species and soot.

The effects of velocities normal to the flame sheet on fuel and soot precursor species that were just described are always present, but are supplemented by the effects of these velocities on soot particles themselves. The effects of these velocities on soot particles are discussed in Refs. 4 and 5 and will be considered only briefly in the following. The reason for differences in the behavior of gaseous soot precursor species and soot particles is that soot particles are too large to have appreciable diffusion velocities and are only convected at local gas velocities. This causes a substantial preferential diffusion effect. Thus, when velocities normal to the flame sheet are directed toward the fuel-lean region, soot particle residence times at fuel-rich conditions (where soot formation occurs) are reduced and the resulting smaller soot particles are more readily oxidized when fuel-lean conditions are reached, reducing soot concentrations and the potential for soot emissions. In contrast, when velocities normal to the flame sheet are directed toward the fuel-rich region, the motion of soot particles toward the oxidizing conditions is blocked, yielding long soot residence times at fuel-rich conditions where soot is formed, which increases soot concentrations and the potential for soot emissions.

The previous discussion clearly shows the importance of velocities normal to the flame sheet on soot processes within diffusion flames. For flames involving coflowing fuel and oxidant streams, these velocities can be controlled by modifying either the velocities or the compositions of the reactant streams. ${ }^{4-8}$ For example, when the oxidant stream velocity is larger than the fuel stream velocity, the flow entrained by the oxidant stream causes velocities normal to the flame sheet to be directed from the fuel side toward the oxidant side of the flame sheet, and vice versa. Thus, several past studies have demonstrated reduced soot concentrations and soot emissions when oxidant/fuel stream velocity ratios are large. ${ }^{4-7}$ Modifying the compositions of the reactant streams provides another way of controlling velocities normal to the flame sheet in coflowing diffusion flames, with corresponding control of soot formation processes. ${ }^{8}$ This approach, however, is more common for the opposed-jet diffusion flame configuration, ${ }^{9}$ and will be considered in that context.

Velocities normal to the flame sheet can be controlled for laminar opposed-jet diffusion flames by shifting the relative positions of the flame sheet and the stagnation plane. In this way, velocities can be modified so that the flow crosses the flame sheet from the fuel-rich to the oxidant-rich side, tending to reduce soot formation. These changes can be caused by modifying the momentum fluxes of the fuel and oxidant streams by varying the mixture fraction at stoichiometric conditions $Z_{\text {st }}$ (Ref. 9). For a diffusion flame having the stoichiometry

$$
\nu_{F}(F)+\nu_{o}(O) \rightarrow \nu_{P}(P)
$$

The parameter $Z_{\mathrm{st}}$ can be found as follows ${ }^{10}$ :

$$
Z_{\mathrm{st}}=Y_{o, a} W_{F} \nu_{F} /\left(Y_{o, a} W_{F} \nu_{F}+Y_{F, f} W_{o} \nu_{o}\right)
$$

From Eq. (2), it is clear that $Z_{\text {st }}$ can be changed by changing the dilution of the fuel and oxidizer streams. For combustion in air, this can be done while keeping the temperature of the flame sheet nearly constant (as a first approximation, barring significant effects of preferential diffusion and radiative heat losses) by shifting nitrogen from the oxidizer to the fuel stream while keeping the total molal flow rates of fuel, oxygen, and nitrogen the same. ${ }^{9}$ For combustion of a hydrocarbon fuel in air using the laminar opposed-jet diffusion flame configuration, the value of $Z_{\text {st }}$ is smallest for the fuel-air combination; therefore, this condition provides the greatest tendencies for soot formation and soot emissions. Another important condition for this parameter is $Z_{\mathrm{st}}=0.5$, where the flame sheet and the stagnation plane coincide; values of $Z_{\text {st }}$ below this limit imply velocities crossing the flame sheet from the fuel-lean side to the fuel-rich side, while values of $Z_{\text {st }}$ above this limit imply the opposite behavior.

Effects of velocities normal to the flame sheet also interact with overall flame residence times to affect soot processes within flames. For example, it is generally possible to increase the strain rates of laminar opposed-jet diffusion flames, having a given value of $Z_{\mathrm{st}}$, to the point where residence times become sufficiently small so that soot formation is inhibited and the flames become blue. ${ }^{9}$ Thus, the main effect of increasing $Z_{\mathrm{st}}$ is to reduce the strain rate at the sooting limit $K_{L}$, as demonstrated by $\mathrm{Du}$ and Axelbaum ${ }^{9}$ for laminar opposed-jet diffusion flames corresponding to ethylene/air combustion. Nevertheless, fastmixing tactics for soot control are only effective to the extent that they increase the available range of flame strain rates between the sooting and extinction limits, with the most attractive conditions involving behavior where soot is absent and the flames are blue for the complete available range of flame strain rates (denoted the permanently-blue-flame regime in the following).

The present investigation seeks to extend recent considerations of the effect of velocities normal to the flame sheet on the propensity of laminar jet diffusion flames to contain and emit soot, ${ }^{4,5,8,9}$ emphasizing the laminar opposed-jet diffusion flame configuration because of its computational tractability for subsequent modeling studies. The objectives are to highlight the functional advantages of manipulating velocities normal to the flame sheet to increase the available range of flame strain rates where the flames neither contain nor emit soot. Thus, new measurements of both the sooting and extinction strain rate limits are reported for hydrocarbon fuels at conditions corresponding to combustion in air at atmospheric pressure. Fuels considered include acetylene, ethylene, ethane, propylene, propane, and 1-3 butadiene.

\section{Experimental Methods}

\section{Apparatus}

The present measurements were carried out using a laminar opposed-jet diffusion flame apparatus similar to $\mathrm{Du}$ and $\mathrm{Ax}$ -

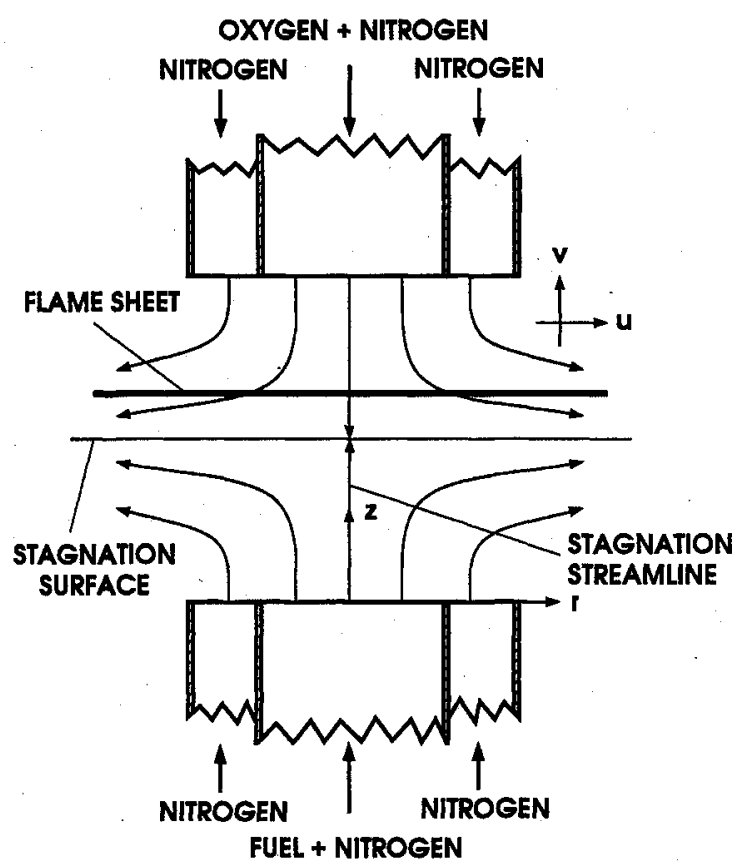

Fig. 1 Sketch of the laminar opposed-jet diffusion flame burner. 
Table 1 Summary of the test flames ${ }^{*}$

\begin{tabular}{llcccc}
\hline \hline & $\begin{array}{c}\text { Molal stoi- } \\
\text { chiometry } \\
\text { fuel/O } / \mathrm{N}_{2}\end{array}$ & $Z_{\text {st }}$ range $^{\mathrm{c}}$ & $\begin{array}{c}Z_{\text {st range }} \\
\text { soot present }\end{array}$ & $\begin{array}{c}K_{L} \text { range, } \\
\mathrm{s}^{-1 d}\end{array}$ & $\begin{array}{c}K_{E} \text { range, } \\
\mathrm{s}^{-1 \mathrm{e}}\end{array}$ \\
\hline $\mathrm{C}_{2} \mathrm{H}_{2}$ & $1.0 / 2.5 / 9.4$ & $0.0701-0.783$ & $0.0704-0.783$ & $50-1110$ & - \\
$\mathrm{C}_{2} \mathrm{H}_{4}$ & $1.0 / 3.0 / 11.3$ & $0.0636-0.782$ & $0.0636-0.350$ & $57-243$ & $1080-1180$ \\
$\mathrm{C}_{2} \mathrm{H}_{6}$ & $1.0 / 3.5 / 13.2$ & $0.0589-0.781$ & $0.0589-0.150$ & $32-68$ & $581-623$ \\
$\mathrm{C}_{3} \mathrm{H}_{6}$ & $1.0 / 4.5 / 16.9$ & $0.0637-0.782$ & $0.0637-0.400$ & $63-255$ & $437-486$ \\
$\mathrm{C}_{3} \mathrm{H}_{8}$ & $1.0 / 5.0 / 18.8$ & $0.0604-0.781$ & $0.0604-0.138$ & $46-103$ & $351-588$ \\
$\mathrm{C}_{4} \mathrm{H}_{6}$ & $1.0 / 5.5 / 20.7$ & $0.0668-0.783$ & $0.0668-0.450$ & $57-426$ & $511-831$ \\
\hline \hline
\end{tabular}

"Laminar opposed-jet diffusion flames with $8.0-\mathrm{mm}$ gap, 10.3-mm-i.d. reactant ports, surrounded by $18.3-\mathrm{mm}-\mathrm{i} . \mathrm{d}$. coflowing nitrogen shroud flows; operating at atmospheric pressure.

${ }^{b}$ Gas purities were as follows: $\mathrm{C}_{2} \mathrm{H}_{2}, 98.0 \% ; \mathrm{C}_{2} \mathrm{H}_{4}, 99.5 \% ; \mathrm{C}_{2} \mathrm{H}_{6}, 99.0 \% ; \mathrm{C}_{3} \mathrm{H}_{6}, 99.0 \% ; \mathrm{C}_{3} \mathrm{H}_{8}, 99.0 \% ; \mathrm{C}_{4} \mathrm{H}_{6}, 99.0 \%$; oxygen, $99.5 \%$; and nitrogen, $99.98 \%$.

${ }^{c}$ Lower limit of $Z_{\mathrm{at}}$ for these flames corresponds to a laminar opposed-jet diffusion flame of fuel and air.

Based on measured velocity gradient near the exit of the airstream for conditions where the flame was blue along the axis based on observations in a darkened room.

Based on the correlation of Sheshadri and Williams. ${ }^{12}$

elbaum. ${ }^{9}$ A sketch of the arrangement appears in Fig. 1. A stable, plane flame was established at the middle of the $8-\mathrm{mm}$ wide gap between the exits of the upper and lower burner tubes, by adjusting the momentum of the fuel and oxidizer streams. Fuel and nitrogen were supplied through the inner tube of the lower part of the burner whereas oxygen and nitrogen were supplied through the inner tube of the upper part of the burner; both of these tubes had an i.d. of $10.3 \mathrm{~mm}$, a wall thickness of $0.4 \mathrm{~mm}$, and a passage length of $200 \mathrm{~mm}$. Annular coflowing streams of nitrogen were applied to both the fuel and oxidizer streams through outer tubes having an i.d. of $18.3 \mathrm{~mm}$ and a wall thickness of $0.4 \mathrm{~mm}$. The objective of the coflowing streams was to eliminate oxidizer entrainment and to minimize disturbances from the surrounding environment. Two honeycomb sections (cell sizes of $1.6 \mathrm{~mm}$ and lengths of $25 \mathrm{~mm}$ ) were located 70 and $140 \mathrm{~mm}$ from the exit of each inner tube to smooth the velocity profiles leaving these tubes. The entire burner assembly could be traversed in the vertical and horizontal directions using stepping-motor-driven linear positioners (having a $5-\mu \mathrm{m}$ positioning accuracy in each direction) to accommodate rigidly mounted optical instrumentation.

Fuel, oxygen, and nitrogen were supplied from commercial cylinders. The gas flows were controlled and metered using pressure regulators and variable area flow meters, which were calibrated with either wet-test or bubble flow meters. Fuel, oxygen, and nitrogen purities are summarized in Table 1.

\section{Instrumentation}

Streamwise velocities along the axis of the flames were measured using single-component laser Doppler velocimetry (LDV). A dual-beam forward-scatter LDV arrangement was used, based on the 514.5-nm line of an argon-ion laser. For these measurements, the reactant streams were seeded with aluminum oxide particles (roughly $1 \mu \mathrm{m}$ nominal diameter). A beam expander, having an expansion ratio of 3.75 , was used in the sending optics to provide a relatively small measuring volume having a diameter and length of 56 and $412 \mu \mathrm{m}$, respectively. The detector output was amplified and processed using a burst counter signal processor (TSI, model 1980B). The resulting experimental uncertainties of velocities $(95 \%$ confidence) generally were less than $3 \%$, dominated by calibration uncertainties.

\section{Procedures}

The soot extinction strain rates $K_{L}$ were based on soot luminosity in the central region of the flame. This property was measured by gradually increasing the flow rates of both the fuel and oxidant streams until the central region of the flame made the transition from yellow-light emission (caused from continuum radiation from soot particles) to blue-light emission (indicating the absence of soot particles) within a darkened room. Note that the present definition of the soot extinction strain rates is based on the absence of soot within the flames, as opposed to an absence of soot particle emissions from the flames (which occurs at lower strain rates). The measurement of $K_{L}$ was somewhat subjective and several observations were made at each condition to help ensure reproducibility.

When the soot extinction condition was reached, the velocities along the stagnation streamline were measured using LDV. The strain rate $K$ was defined in terms of the slope of the velocity profile ahead of the preheat zone on the oxidizer side, similar to the past work of Du et al., ${ }^{11}$ as follows:

$$
K=-\left(\frac{\partial v}{\partial z}\right)_{z \rightarrow a}
$$

Considering both observer-to-observer variations of the determination of the soot extinction condition, and the corresponding uncertainties of the measurements of strain rate, it is estimated that experimental uncertainties of $K_{L}$ (95\% confidence) are less than $20 \%$. Effects of various levels of room lighting can yield larger variations of $K_{L}$, however, as discussed later.

The critical flame-extinction strain rate $K_{E}$ was measured by increasing reactant flow rates past the soot extinction condition until the flame extinguished abruptly. Seeding particle densities were too large for LDV measurements near the flame extinction conditions; therefore, flame extinction strain rates were estimated using the formulation of Seshadri and Williams, ${ }^{12}$ as follows:

$$
K=\left(2\left|v_{a}\right|\right)\left[1+\left(v_{f} /\left|v_{a}\right|\right)\left(\rho_{f} / \rho_{a}\right)^{1 / 2}\right] / L
$$

where $v_{a}$ and $v_{f}$ are the mean velocities of the reactant streams at the burner exits, which are known from the flow rates of these streams and the burner geometry.

The correlation of Eq. (4) was evaluated over a range of operating conditions for all of the fuels considered during the present investigation. These results are illustrated in Fig. 2 where the present measurements of strain rates are plotted along with estimates based on Eq. (4). The agreement between the correlation and measurements is seen to be reasonably good, with uncertainties of the correlation (95\% confidence) less than $6 \%$. When these results are combined with the uncertainties of specifying extinction conditions, it is estimated that the experimental uncertainties (95\% confidence) of $K_{E}$ are less than $15 \%$.

\section{Test Conditions}

The ranges of test conditions for the present investigation are summarized in Table 1. Fuels considered included acetylene, ethylene, ethane, propylene, propane, and 1-3 butadiene. The molal ratios listed in the table were maintained as $Z_{\mathrm{st}}$ was varied to provide a constant flame sheet temperature (as a first 


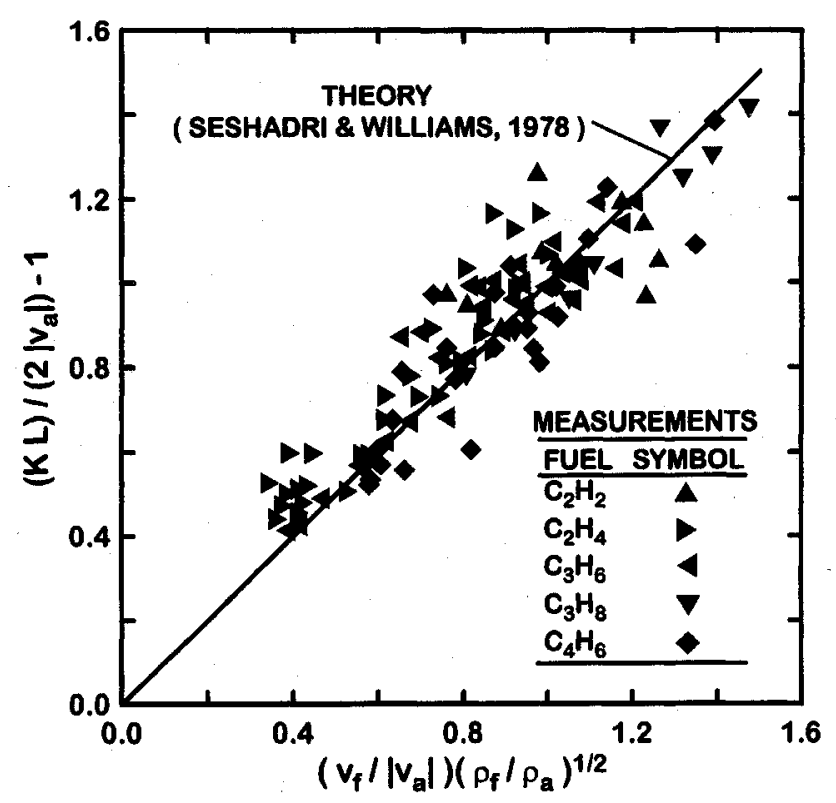

Fig. 2 Correlation between strain rates and burner port exit conditions for various test fuels.

approximation, barring significant effects of preferential diffusion and radiative heat losses, as noted earlier) while corresponding to combustion in air. ${ }^{9}$ As a practical matter, however, shifting $Z_{\text {st }}$ involves considerable variations of the concentrations of fuel and oxidizing species so that the reactive environment of the flame certainly was not invariant with respect to processes of soot formation and oxidation. For example, the smallest values of $Z_{\mathrm{st}}$ correspond to opposed-jets of air and pure fuel, whereas the largest values of $Z_{\mathrm{st}}$ correspond to opposed-jets of pure oxygen and fuel that is substantially diluted by nitrogen. Clearly, the large $Z_{\text {st }}$ condition is much less conducive to soot formation (when flame temperatures are not varied significantly) because increased concentrations of oxygen at fuel-lean conditions tend to enhance rates of soot oxidation, whereas decreased concentrations of fuel at fuelrich conditions tend to inhibit rates of soot formation. ${ }^{13-15}$ Thus, in contrast to manipulating fuel- and oxidizer-stream velocity ratios (as in Ref. 4), which mainly affect velocities normal to the flame sheet, varying $Z_{\mathrm{st}}$ to change velocities normal to the flame sheet (as in the present study) also modifies other soot-forming properties of the test flames. Thus, attributing present observations solely to effects of velocities normal to the flame sheet must be tempered by the potential effects of other associated changes of flame properties when these velocities are varied.

In Table 1 , the $Z_{\text {st }}$ range of the experiments is bounded at the lower limit by an opposed-jet diffusion flame of fuel and air, and at the upper limit by an opposed-jet diffusion flame of a fuel-nitrogen mixture and oxygen. Except for acetylene, conditions were encountered at large $Z_{\text {st }}$ where the flames remained blue over the complete range of flame strain rates that could be achieved; therefore, the $Z_{\mathrm{st}}$ range where soot was present is generally more limited than the available $Z_{\text {st }}$ range. The strain rates $K_{L}$ were determined for all of the fuels within the range of conditions where soot was present. The strain rates $K_{E}$ were determined for all of the fuels except acetylene. Unfortunately, the $K_{E}$ limit could not be measured for acetylene because these flames became too large for safe operation of the apparatus before the extinction condition was reached.

\section{Results and Discussion}

\section{Flow Properties}

Typical properties along stagnation streamlines are illustrated for acetylene-fueled flames having various values of $Z_{\mathrm{st}}$ in Fig. 3. Properties plotted in Fig. 3 include velocities, the positions of the flame sheet and the stagnation plane, and the region containing soot particles. The test conditions involve constant molal ratios of fuel, oxygen, and nitrogen to provide constant flame temperatures (as a first approximation, barring significant effects of preferential diffusion and radiative heat losses, as noted earlier), and constant strain rates (within 122$127 \mathrm{~s}^{-1}$ ) found by the LDV measurements; for $Z_{\mathrm{st}}=0.2,0.3$, 0.5, and 0.7. Distances noted in Fig. 3 are measured from the exit of the oxidizer stream passage, which corresponds to the left-hand side of the plots.

The condition nearest direct combustion of acetylene in air in Fig. 3 is $Z_{\text {st }}=0.2$. At this condition, $Z_{\text {st }}<0.5$, the flame sheet is on the oxidizer side of the stagnation plane and there is a thick yellow luminous region containing soot particles extending from near the fuel-rich side of the flame sheet to near the flame sheet side of the stagnation plane. Soot particle motion in this region involves nucleation near the flame sheet and then subsequent convection toward the stagnation plane, which provides an extended region for soot growth. Soot particles subsequently convect radially outward near the stagnation plane, yielding a trace of soot emissions at this condition. With further reductions of $Z_{\text {st, }}$ the flame sheet and the stagnation plane move even farther apart, yielding increased degrees of soot formation and soot emissions.

When $Z_{\text {st }}$ is increased to 0.3 , results illustrated in Fig. 3 show that the thickness of the soot-containing region decreases, yielding somewhat reduced yellow luminosity near the axis of the flame. Nevertheless, the main features of soot processes for $Z_{\mathrm{st}}=0.2$ and 0.3 are similar because both involve $Z_{\mathrm{st}}<0.5$ : soot nucleates near the flame sheet and then convects toward the stagnation plane at fuel-rich conditions, providing relatively long residence times at conditions that favor soot formation. The somewhat reduced residence time in the soot formation region for $Z_{s t}=0.3$, however, limits soot formation sufficiently so that soot emissions are no longer observed.

When $Z_{\mathrm{st}}=0.5$ in Fig. 3, as noted earlier, the singular condition is reached where the flame sheet and the stagnation

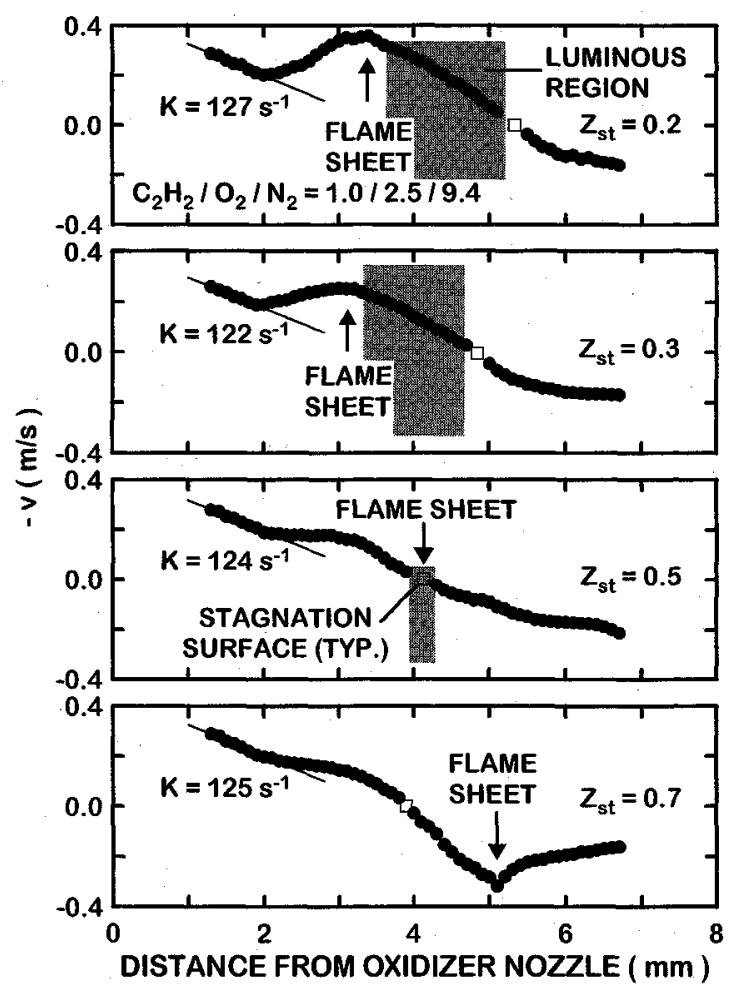

Fig. 3 Velocity profiles along the axis of laminar opposed-jet diffusion flames of $\mathrm{C}_{2} \mathrm{H}_{2} / \mathrm{O}_{2} / \mathrm{N}_{2}$ having a molal stoichiometry of 1.0 / 2.5/9.4 for various $Z_{\mathrm{at}}$. 
plane coincide. Then, the soot-containing region becomes a relatively narrow zone near the flame sheet, the yellow luminosity of the flame near its axis becomes relatively weak, and there are no soot emissions. These conditions are similar to soot processes along the axis of laminar coflowing jet diffusion flames, as described in Refs. 4, 5, and 13-15. Thus, soot particles begin to nucleate and grow once sufficiently high temperatures are reached on the fuel-rich side of the flame sheet, and these materials are subsequently drawn toward the stagnation plane that is at the flame sheet. Then, since soot oxidation conditions actually extend to fuel-rich conditions (measurements reported in Refs. 13 and 14 suggest that significant levels of soot oxidation extend to fuel-equivalence ratios as large as 1.14), the soot oxidizes completely as it approaches the stagnation plane for these conditions, yielding relatively low soot concentrations within the flame and no soot emissions.

Finally, when $Z_{\text {st }}=0.7, Z_{\text {st }}>0.5$ and the flame sheet is on the fuel side of the stagnation plane. This provides conditions where the residence times of fuel and soot precursors are too small to actually generate soot particles before these materials pass into a region where they can be oxidized to become conventional combustion products. Thus, this flame is entirely blue because no soot particles are present to emit continuum radiation. Taken together, the results of Fig. 3 show that modifying velocities normal to the flame sheet provides a mechanism to control soot formation in addition to conventional increases of mixing rates by increasing flame strain rates, although corresponding effects of changing fuel and oxygen concentrations as these velocities are changed may also be a factor, as noted earlier. Quantifying the important relationship between $Z_{\mathrm{st}}$ and $K_{L}$ for all of the test fuels will be considered next.

\section{Critical Strain Rates}

Soot and flame extinction strain rates are plotted as a function of $Z_{\text {st }}$ for ethylene-fueled flames in Fig. 4. These flames involved relative molal flow rates corresponding to combustion in air, as discussed earlier. The lowest value of $Z_{\mathrm{st}}=0.0636$ is marked on the plot; this condition corresponds to conventional combustion in air. As noted earlier, $K_{L}$ was mainly based on direct measurements (which is designated LDV measurements in Fig. 4 and in subsequent plots), whereas $K_{E}$ was based on the correlation of Ref. 12 given by Eq. (4) (which is designated EST measurements in Fig. 4 and in subsequent plots). Measurements of $K_{L}$ were also obtained based on Eq. (4) (the EST procedure) and are plotted on the figure; these results are seen to agree very well with the direct measurements of $K_{L}$ by LDV (the LDV procedure), which is reasonable based on the earlier discussion in connection with Fig. 2 . In addition to the present measurements, the values of $K_{L}$ measured directly by LDV (the LDV procedure) from Du and Axelbaum ${ }^{9}$ also are shown on the plot.

It is evident that the values of $K_{L}$ observed by $\mathrm{Du}$ and $\mathrm{Ax}$ elbaum, ${ }^{9}$ and during the present investigation, both decrease with increasing $Z_{\text {st }}$. In the region where they overlap, however, the values of $K_{L}$ from $\mathrm{Du}$ and Axelbaum consistently are approximately $50 \mathrm{~s}^{-1}$ smaller than the present measurements. It is felt that these differences probably caused by effects of room illumination during the measurements. In particular, present measurements were made under darkroom conditions, whereas results agreeing with $\mathrm{Du}$ and Axelbaum could be obtained at higher levels of room illumination. Similar to the observations of $\mathrm{Du}$ and Axelbaum, there is a linear correlation between $K_{L}$ and $Z_{\mathrm{st}}$ at lower values of $Z_{\mathrm{st}}$, which correspond to higher values of $K_{L}$. At lower values of $K_{L}$, however, effects of buoyancy, and possibly heat losses to the burner lips and from radiation, become important and the measurements deviate from the linear correlation and approach a constant minimum value of $K_{L}$. It would be very interesting to determine whether similar behavior was observed in the absence of buoyancy, which

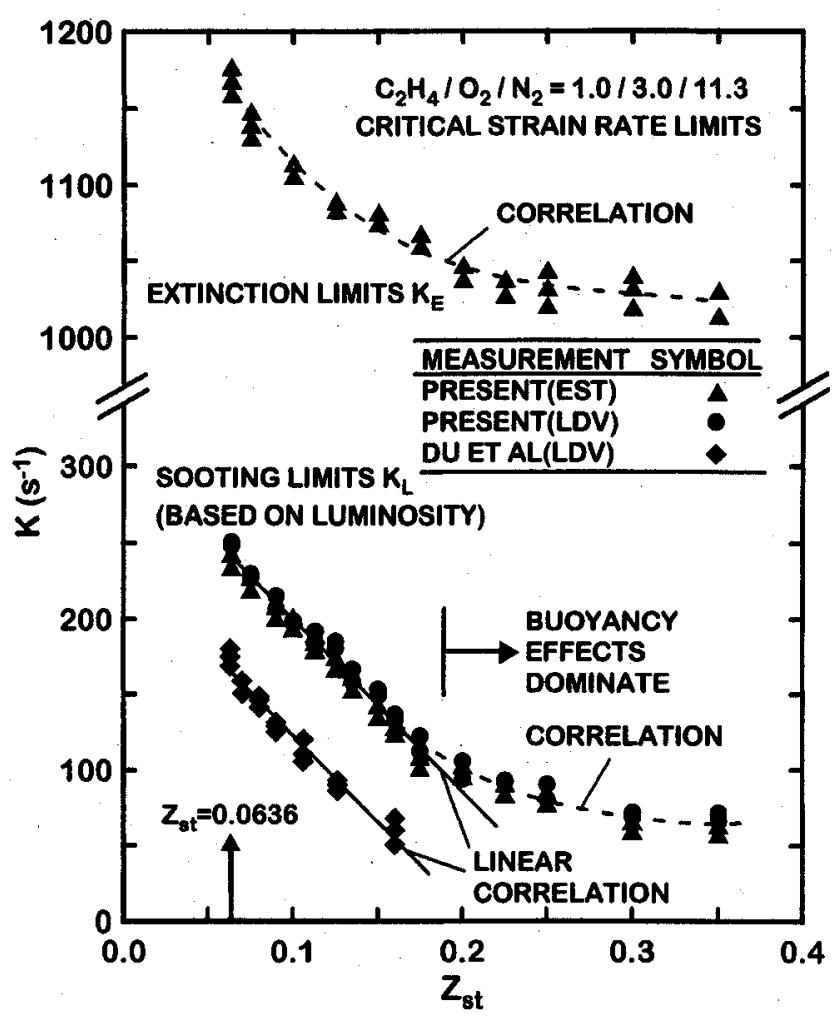

Fig. 4 Critical strain rates as a function of $Z_{\text {st }}$ for laminar opposed-jet diffusion flames of $\mathrm{C}_{2} \mathrm{H}_{4} / \mathrm{O}_{2} / \mathrm{N}_{2}$ having a molal stoichiometry of 1.0/3.0/11.3.

would provide insight about the relative contributions of buoyancy and heat losses to the properties of the minimum $K_{L}$. These flames became totally soot free at all available stretch rates (which is the permanently-blue-flame regime, defined earlier) when $Z_{\text {st }} \geq 0.35$, which still involves conditions where flow velocities normal to the flame sheet are directed from the fuel-lean side to the fuel-rich side of the flame sheet (recall that $Z_{\mathrm{st}}=0.5$ is the limiting condition where the flame sheet and the stagnation plane coincide). This behavior provides evidence that effects of mean velocities normal to the flame sheet on soot concentrations are being supplemented by other effects when these velocities are changed by changing $Z_{\text {st }}$ for the present flame configuration. This includes effects of increased oxygen concentrations at fuel-lean conditions and decreased fuel concentrations at fuel-rich conditions as $Z_{s t}$ is increased, both of which should tend to reduce soot concentrations as mentioned earlier. Another factor is that gaseous species responsible for soot formation have velocities that involve both mean and diffusion velocities so that mean velocities normal to the flame sheet are not the sole factor controlling their motion (although mean velocities do dominate the motion of heavy hydrocarbons and soot because of their small diffusivities).

Values of $K_{E}$ illustrated in Fig. 4 decrease similar to $K_{L}$ as $Z_{\mathrm{st}}$ increases. Nevertheless, the reduction of $K_{L}$ compared to $K_{E}$ as $Z_{\mathrm{st}}$ increases (as a percentage) is much greater, so that there is a larger range of stretch rates where soot is avoided while a stable flame can still be maintained. Naturally, once $Z_{\text {st }}$ exceeds the permanently-blue-flame limit, no soot is observed for any stretch rate where a stable flame can be maintained. This result clearly highlights the subtle but important influence of $Z_{\text {st }}$ on soot processes within diffusion flames through its effect on velocities normal to the flame sheet and on other soot-forming properties of the present flames.

While ethylene flames reach the permanently-blue-flame regime for $Z_{s t}<0.5$, which involves a range of conditions where the flow crosses the flame sheet from the fuel-rich to the fuel- 
lean sides, acetylene flames illustrate contrasting behavior where the permanently-blue-flame regime was never observed, even for the accessible range of $Z_{\text {st }}>0.5$, where the flow crosses the flame sheet from the fuel-rich to the fuel-lean sides. These results are illustrated in Fig. 5 where $K_{L}$ is plotted as a function of $Z_{s t}$ for acetylene-fueled flames. As noted earlier, corresponding measurements of $K_{E}$ could not be made for the acetylene flames. Similar to the ethylene flames, the correlation between $K_{L}$ and $Z_{\mathrm{st}}$ is linear at low values of $Z_{\mathrm{s}}$, but $K_{L}$ becomes nearly constant at large values of $Z_{\text {st }}$, probably because of the effects of buoyancy and heat losses. The stronger sooting tendencies of acetylene in comparison to ethylene are reflected by the larger values of $K_{L}$ for acetylene at each $Z_{\mathrm{st}}$. Nevertheless, the use of larger values of $Z_{\text {st }}$ still provides a means of reaching soot-free behavior at modest values of $K_{L}$. Similarly, reaching higher values of $Z_{\text {st }}$, perhaps by diluting the oxidant stream with a low-density gas like helium, might yield

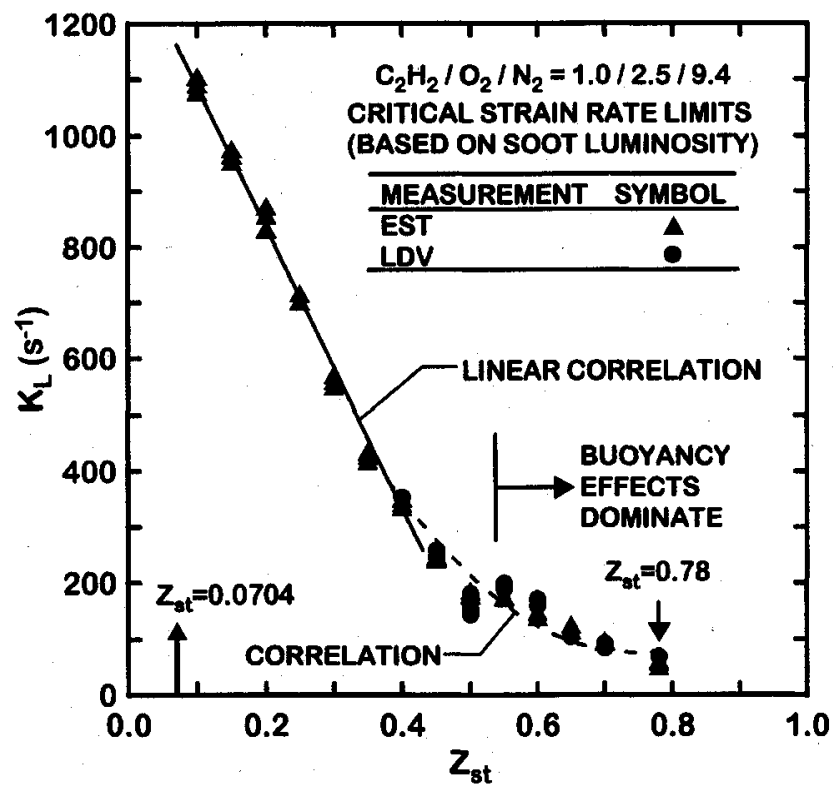

Fig. 5 Critical strain rates as a function of $Z_{\text {st }}$ for laminar opposed-jet diffusion flames of $\mathrm{C}_{2} \mathrm{H}_{2} / \mathrm{O}_{2} / \mathrm{N}_{2}$ having a molal stoichiometry of 1.0/2.5/9.4.

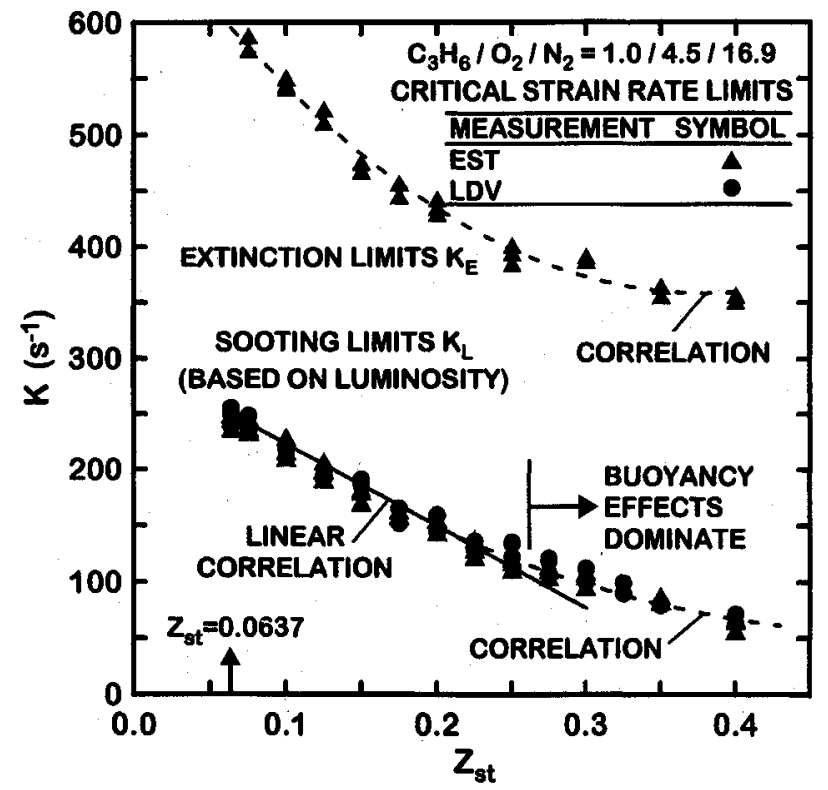

Fig. 6 Critical strain rates as a function of $Z_{\mathrm{at}}$ for laminar opposed-jet diffusion flames of $\mathrm{C}_{3} \mathrm{H}_{6} / \mathrm{O}_{2} / \mathrm{N}_{2}$ having a molal stoichiometry of 1.0/4.5/16.9. conditions where a permanently-blue-flame regime is observed, as before, however, this must still be assessed. Naturally, similar behavior might be achieved more directly by controlling the velocity ratios for practical diffusion flame configurations, as discussed in Ref. 4, but proof of this behavior still must be sought.

Similar results for propylene, 1-3 butadiene, propane, and ethane-fueled flames are illustrated in Figs. 6-9, respectively. In all cases, $K_{L}$ and $K_{E}$ decrease as $Z_{\text {st }}$ increases, in a linear fashion at first and then tending to approach constant limiting values of $K_{L}$ and $K_{E}$ as $Z_{\text {st }}$ becomes large. As expected, values of $K_{L}$ tend to reflect the generally accepted sooting tendency of the fuels, which is usually represented by the laminar smoke point properties discussed by Schug et al. ${ }^{16}$ Values of $Z_{\text {st }}$, required to reach the permanently-blue-flame regime also crudely correlate in terms of the propensity of the fuel to soot, i.e., larger values of $Z_{\mathrm{st}}$, are needed to reach this condition for

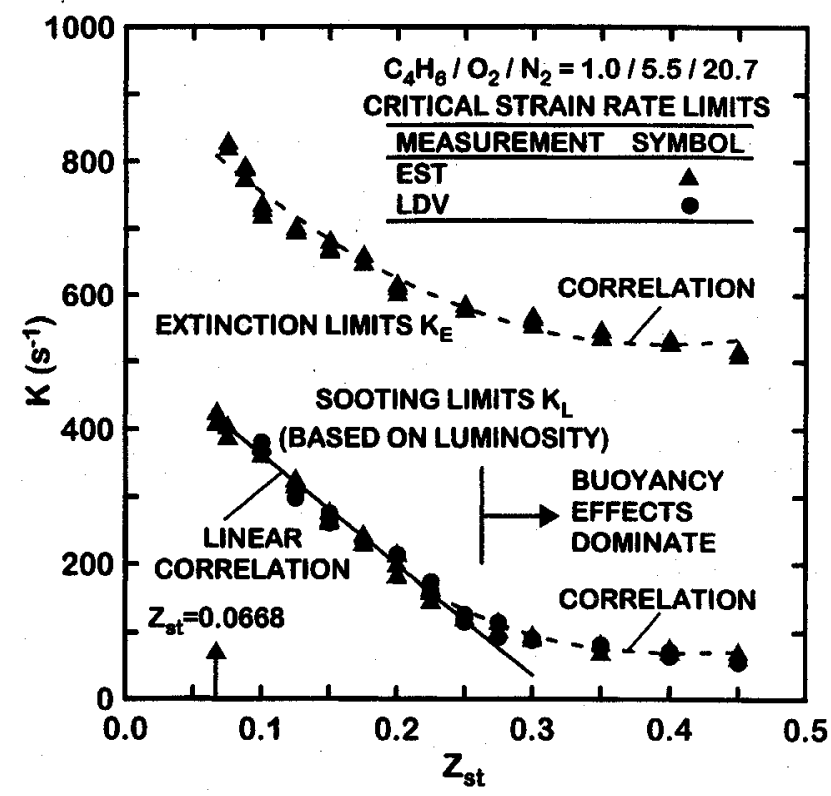

Fig. 7 Critical strain rates as a function of $Z_{\text {st }}$ for laminar opposed-jet diffusion flames of $\mathrm{C}_{4} \mathrm{H}_{6} / \mathrm{O}_{2} / \mathrm{N}_{2}$ having a molal stoichiometry of 1.0/5.5/20.7.

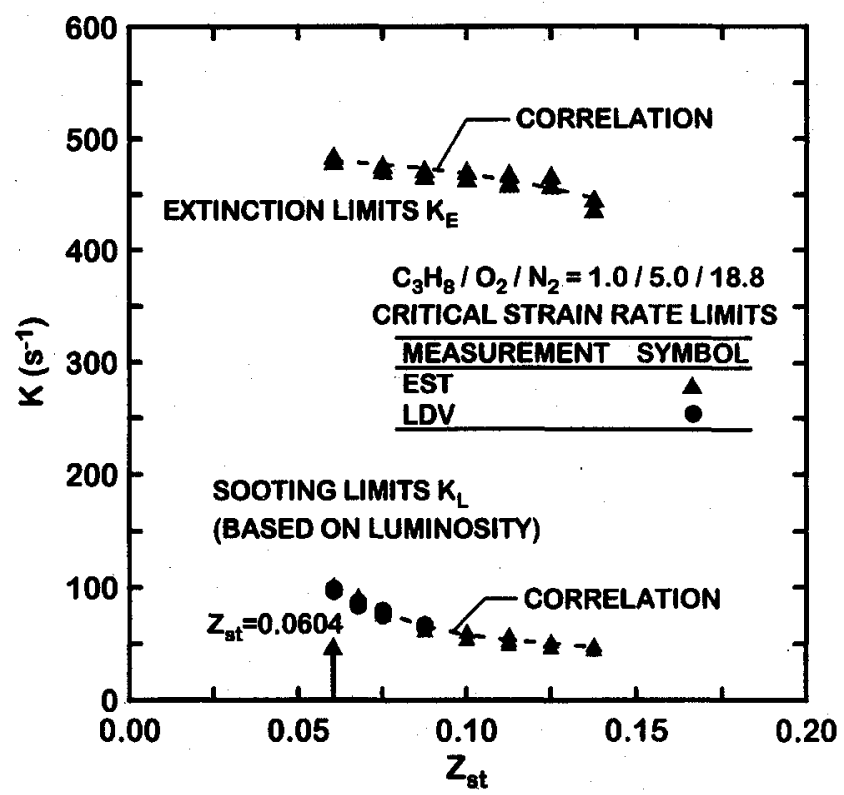

Fig. 8 Critical strain rates as a function of $Z_{\mathrm{st}}$ for laminar opposed-jet diffusion flames of $\mathrm{C}_{3} \mathrm{H}_{8} / \mathrm{O}_{2} / \mathrm{N}_{2}$ having a molal stoichiometry of 1.0/5.0/18.8. 
the more heavily sooting fuels. In particular, these limits are quite low for the lightly sooting saturated paraffin fuels, e.g., $Z_{\mathrm{st}}=0.14$ and 0.13 is required to reach the permanently-blueflame regime for propane and ethane.

\section{Extinction Properties}

An important flame property is the range of conditions where stable soot-free flames can be obtained. This property is illustrated in Fig. 10 , where the ratio $K_{E} / K_{L}$ is plotted as a function of $Z_{\text {st }}$, for ethane-, propane-, ethylene-, 1-3 butadiene-, and propylene-fueled flames. Similar results could not be illustrated for acetylene-fueled flames because $K_{E}$ could not be found for this fuel as discussed earlier. The results illustrated in the figure are limited at low $Z_{\text {st }}$, by fuel/air flames and at large $Z_{\text {st }}$, by the onset of the permanently-blue-flame regime.

Flexibility in achieving soot-free combustion is best obtained when $K_{E} / K_{L}$ is large because strain rates needed to eliminate soot can be achieved at a small fraction of strain rates where flame stability becomes a problem. Thus, it is evident from the results illustrated in Fig. 10 that increasing $Z_{\text {st }}$ clearly

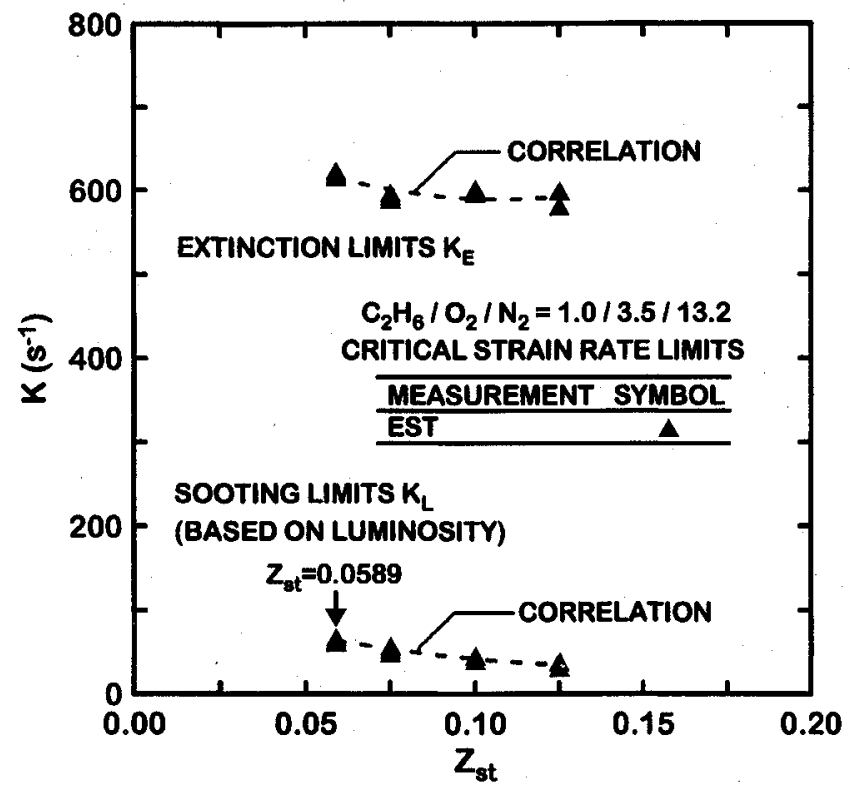

Fig. 9 Critical strain rates as a function of $Z_{\text {st }}$ for laminar opposed-jet diffusion flames of $\mathrm{C}_{2} \mathrm{H}_{6} / \mathrm{O}_{2} / \mathrm{N}_{2}$ having a molal stoichiometry of 1.0/3.5/13.2.

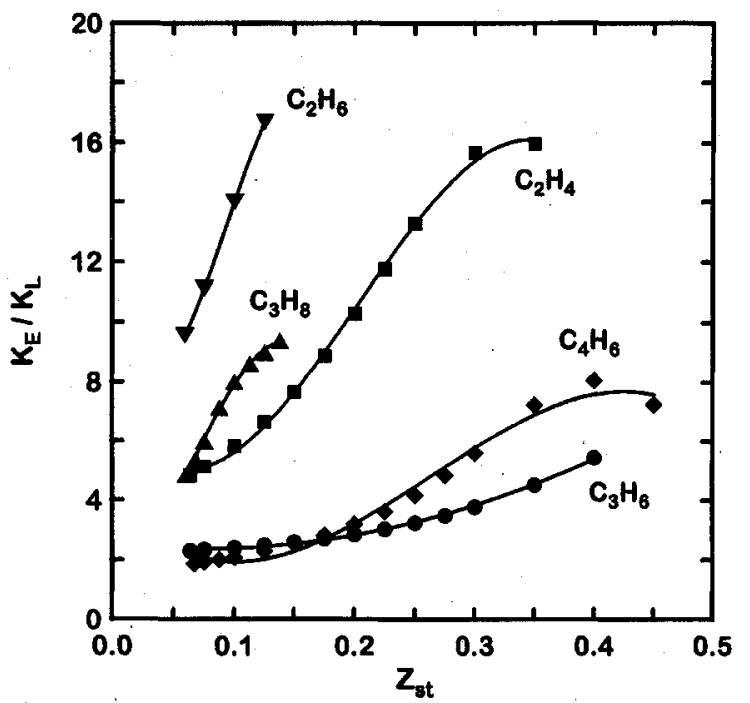

Fig. 10 Extinction-to-sooting limit ratios as a function of $Z_{\mathrm{at}}$ for laminar opposed-jet diffusion flames of various fuels. enhances the potential for soot-free combustion in a diffusion flame. Even more interesting is the range of conditions where the flames are blue for all values of $K$, the permanently-blueflame regime, which implies that $K_{E} / K_{L}$ becomes infinite. For this range of conditions, the concept of fast mixing for soot reduction becomes a misnomer because any mixing rate provides soot-free combustion.

There is a general correspondence between values of $K_{E} / K_{L}$ and the $Z_{\mathrm{st}}$ required to reach the permanently-blue-flame regime, and other measures of the tendency of a fuel to soot, such as laminar smoke point properties. Thus, lightly sooting fuels, such as ethane and propane, exhibit relatively large values of $K_{E} / K_{L}$ and reach the permanently-blue-flame regime at a relatively low value of $Z_{\text {st. }}$. On the other hand, heavily sooting fuels, such as 1-3 butadiene and propylene, have relatively low values of $K_{E} / K_{L}$ and require relatively large values of $Z_{\mathrm{st}}$ to reach the permanently-blue-flame regime. Similar behavior was generally observed for laminar coflowing-jet diffusion flames in terms of the air/fuel velocity ratio, ${ }^{4}$ although the presence of a permanently-blue-flame regime has not yet been established for this somewhat more practical approach to achieve soot control by fast mixing concepts.

\section{Conclusions}

Effects of flow properties on the soot properties of hydrocarbon-fueled laminar opposed-jet diffusion flames were studied experimentally at atmospheric pressure, considering acetylene, ethylene, ethane, propylene, propane, and 1-3 butadiene as fuels. The main focus was on effects of velocities normal to the flame sheet, which were varied by varying the stoichiometric mixture fraction of the flames while maintaining a constant flame temperature (as a first approximation, barring significant effects of preferential diffusion and radiative heat losses). The main conclusions of the study are as follows:

1) Both soot and flame extinction strain rates progressively decreased as the stoichiometric mixture fraction was increased, with present behavior for soot extinction strain rates when effects of buoyancy were small confirming earlier observations by $\mathrm{Du}$ and Axelbaum. ${ }^{9}$ The main mechanism for this behavior, supported by earlier study of effects of hydrodynamics on laminar smoke points, ${ }^{4}$ is thought to involve a tendency for velocities normal to the flame sheet to be more directed from the fuel to the oxidant side of the flame as the stoichiometric mixture fraction is increased, which reduces residence times at conditions where rates of soot formation are greatest. Nevertheless, variations of the stoichiometric mixture fraction also modify other aspects of the soot-forming environment of the present flames, and the contribution of these effects to reduced soot extinction strain rates must still be resolved.

2) Increasing the stoichiometric mixture ratio tends to increase $K_{E} / K_{L}$, which provides more flexibility for obtaining soot-free flames at modest strain rates where flame stability is assured. More importantly, except for acetylene, all of the fuels exhibited a limiting value of the stoichiometric mixture ratio, beyond which the flames became completely soot free for all strain rates in a permanently-blue-flame regime, so that fast mixing was no longer a requirement to control soot. The present effects of stoichiometric mixture ratios on soot processes in opposed-jet diffusion flames parallel more practical effects of air/fuel velocity ratios in coflowing-jet diffusion flames, however, the existence of a corresponding regime of velocity ratios that yield soot-free flames at all strain rates, or permanently-blue flames, must still be established.

3) Conventional measures of the propensity of a fuel to soot, e.g., laminar smoke point properties, parallel effects of soot extinction strain rates and stoichiometric mixture ratios observed during the present investigation. Thus, fuels that have a greater propensity to soot have lower values of $K_{E} / K_{L}$ and larger values of $Z_{\text {st }}$ are required to reach the permanently-blueflame regime, which implies somewhat reduced flexibility for achieving soot-free flames. Finally, while values of $Z_{\text {st }}$ for the 
onset of the permanently-blue-flame regime tend to increase as the sooting tendency of the fuel increased, this limit was observed for $Z_{\text {st }}$ both smaller and larger than 0.5 ; therefore, completely soot-free flame conditions are not particularly correlated with conditions where velocities normal to the flame sheet are directed from the fuel-rich to the fuel-lean side, as suggested in some earlier work, e.g., Refs. 4 and 5 . This behavior should motivate study of other effects of $Z_{\text {st }}$ on the sootforming tendency of the present flames, e.g., modified fuel and oxygen concentrations in the fuel-rich and fuel-lean regions, respectively.

\section{Acknowledgments}

This research was supported by the Office of Naval Research Grant N00014-93-0321, under the technical management of G. D. Roy; and NASA Grant NAG3-1245 under the technical management of D. L. Urban of the NASA Lewis Research Center.

\section{References}

'Glassman, I., "Soot Formation in Combustion Processes," 22nd Symposium (International) on Combustion, The Combustion Inst., Pittsburgh, PA, 1988, pp. 295-311.

${ }^{2}$ Haynes, B. S., and Wagner, H. G., "Soot Formation," Progress in Energy and Combustion Science, Vol. 7, No. 4, 1981, pp. 229273.

${ }^{3}$ Bahr, D. W., "Gas Turbine Engine Emission Abatement-Status and Needed Advancements," Gas Turbine Combustor Design Problems, edited by A. H. Lefebvre, Hemisphere, Washington, DC, 1979, pp. 205-223.

${ }^{4}$ Lin, K.-C., and Faeth, G. M., "'Hydrodynamic Suppression of Soot Emissions in Laminar Diffusion Flames," Journal of Propulsion and Power, Vol. 12, No. 1, 1996, pp. 10-17.

5Sunderland, P. B., Mortazavi, S., Faeth, G. M., and Urban, D. L., "Laminar Smoke Points of Nonbuoyant Jet Diffusion Flames," Combustion and Flame, Vol. 96, No. 1, 1994, pp. 97-103.
${ }^{6}$ Hussman, A. W., and Maybach, G. W., "The Film Vaporizer Combustor,' SAE Transactions, Vol. 69, 1961, pp. 563-574.

${ }^{7} \mathrm{Wu}$, K.-T., and Essenhigh, R. H., "Mapping and Structure of Inverse Diffusion Flames of Methane," 20th Symposium (International) on Combustion, The Combustion Inst., Pittsburgh, PA, 1984, pp. 1925-1932.

${ }^{8}$ Sugiyama, G., "Nonluminous Diffusion Flame of Diluted Acetylene in Oxygen Enriched Air," 25th Symposium (International) on Combustion, The Combustion Inst., Pittsburgh, PA, 1994, pp. $601-$ 608.

${ }^{9} \mathrm{Du}$, J., and Axelbaum, R. L., “The Effect of Flame Structure on Soot-Particle Inception in Diffusion Flames," Combustion and Flame, Vol. 100 , No. 3, 1995, pp. 367-375.

${ }^{10}$ Williams, F. A., Combustion Theory, Benjamin/Cummings, Menlo Park, CA, 1985.

${ }^{11} \mathrm{Du}$, J., Axelbaum, R. L., and Law, C. K., "Experiments on the Sooting Limits of Aerodynamically-Strained Diffusion Flames," 22nd Symposium (International) on Combustion, The Combustion Inst., Pittsburgh, PA, 1988, pp. 387-394.

${ }^{12}$ Seshadri, K., and Williams, F. A., "Laminar Flow Between Parallel Plates with Injection of a Reactant at High Reynolds Number," International Journal of Heat and Mass Transfer, Vol. 21, No. 2, 1978, pp. 251-253.

${ }^{13}$ Sunderland, P. B., Köylü, Ü. Ö., and Faeth, G. M., "'Soot Formation in Weakly-Buoyant Acetylene-Fueled Laminar Jet Diffusion Flames Burning in Air," Combustion and Flame, Vol. 100, Nos. 1, 2, 1995, pp. 310-322.

${ }^{14}$ Sunderland, P. B., and Faeth, G. M., "'Soot in Hydrocarbon/Air Laminar Jet Diffusion Flames," Combustion and Flame, Vol. 105, Nos. 1,2, 1996, pp. 132-146.

${ }^{15}$ Lin, K.-C., Sunderland, P. B., and Faeth, G. M., "'Soot Nucleation and Growth in Acetylene/Air Laminar Coflowing Jet Diffusion Flames," Combustion and Flame, Vol. 104, No. 3, 1996, pp. 369375.

${ }^{16}$ Schug, K. P., Manheimer-Timnat, Y., Yaccarino, P., and Glassman, I., "Sooting Behavior of Gaseous Hydrocarbon Diffusion Flames and the Influence of Additives," Combustion Science and Technology, Vol. 22, Nos. 5,6, 1980, pp. 235-250. 